\title{
BMJ Open Sputum eosinophilia is a determinant of FEV1 decline in occupational asthma: results of an observational study
}

\author{
Donatella Talini, ${ }^{1}$ Federica Novelli, ${ }^{2}$ Elena Bacci, ${ }^{2}$ Marialaura Bartoli, ${ }^{2}$ \\ Silvana Cianchetti, ${ }^{2}$ Francesco Costa, ${ }^{2}$ Federico L Dente, ${ }^{2}$ Antonella Di Franco, ${ }^{2}$ \\ Manuela Latorre ${ }^{2}$ Laura Malagrinò, ${ }^{2}$ Barbara Vagaggini, ${ }^{2}$ Alessandro Celi, ${ }^{2}$ \\ Pierluigi Paggiaro
}

To cite: Talini D, Novelli $F$, Bacci E, et al. Sputum eosinophilia is a determinant of FEV1 decline in occupational asthma: results of an observational study. BMJ Open 2015:5:e005748. doi:10.1136/bmjopen-2014005748

- Prepublication history and additional material is available. To view please visit the journal (http://dx.doi.org/ 10.1136/bmjopen-2014005748).

Received 21 May 2014 Revised 15 July 2014 Accepted 24 July 2014

\section{(a) CrossMark}

${ }^{1}$ Regione Toscana, CERIMP, Pisa, Italy

${ }^{2}$ Department of Surgery, Medicine, Molecular Biology and Critical Care, University of Pisa, Pisa, Italy

Correspondence to Dr Donatella Talini; d.talini@usI5.toscana.it

\section{ABSTRACT}

Objective: To evaluate the potential determinants of forced expiratory volume in $1 \mathrm{~s}$ (FEV1) decline in workers with occupational asthma (OA) still exposed to the causative agent. We hypothesised that sputum eosinophilia might be a predictor of poor asthma outcome after diagnosis.

Setting, design and participants: In a specialistic clinical centre of the University Hospital of Pisa, we studied 39 participants $(28 \mathrm{M}, 11 \mathrm{~F}$ ) diagnosed as having OA, routinely followed up between 1990 and 2009. They were a subgroup of 94 participants diagnosed as affected by $O A$ in that period: 9 had been removed from work at the diagnosis, 21 were excluded for having ceased occupational exposure after few months from diagnosis, and 25 were lost at the follow-up or had no acceptable sputum measurements at the diagnosis. Estimates of the decline in FEV1 were obtained by means of simple regression analysis during the period of occupational exposure after diagnosis. Logistic regression was used to analyse the effects of factors (baseline FEV1 and sputum inflammatory cells, duration and type of exposure) that may potentially influence FEV1 decline.

Results: At follow-up (5.7+3.7 years), most participants were still symptomatic despite inhaled corticosteroids (ICS) treatment and had their occupational exposure reduced. Participants with higher sputum eosinophils (>3\%) at baseline had a significantly greater decline of FEV1 ( -52.5 vs $-18.6 \mathrm{~mL} / \mathrm{year}, \mathrm{p}=0.012)$. Logistic regression showed that persistent exposure and sputum eosinophilia were significantly associated with a greater decline in FEV1 $(\mathrm{OR} 11.5,95 \% \mathrm{Cl} 1.8$ to 71.4, $\mathrm{p}=0.009$ and $\mathrm{OR} 6.7,95 \% \mathrm{Cl} 1.1$ to 41.7 , $p=0.042$, respectively).

Conclusions: Sputum eosinophilia at diagnosis, together with the persistence of occupational exposure during follow-up, may contribute to a greater decline in FEV1 in patients with OA still at work. Further long-term studies are required as to whether intensive ICS treatment may be beneficial for patients with $\mathrm{OA}$ and increase ad eosinophilic inflammation.

\section{Strengths and limitations of this study}

- In our study, we found a significant relationship between baseline sputum eosinophil levels and forced expiratory volume in $1 \mathrm{~s}$ (FEV1) decline, suggesting that higher levels of inflammation at baseline may cause an accelerated decline in FEV1.

- No previous paper has considered this biomarker as a possible determinant of the decline in FEV1 in patients with occupational asthma who continued to work.

- The number of patients examined is relatively small. However, apart from few studies enrolling a large number of patients, several other published studies have included a similar number of patients.

- The type of exposure (low-molecular-weight compound vs high-molecular-weight compound) was heterogeneous, but again this is frequently reported in many previous studies.

- The distinction between persistence and reduction of exposure is not based on specific environmental measurements, but the majority of previous studies used the same rough distinction we did between patients who continued and patients who reduced occupational exposure to a specific sensitiser.

\section{INTRODUCTION}

Participants with occupational asthma (OA) often experience permanent sequelae after removal from exposure, and the outcome of OA after diagnosis is often poor. A substantial body of data indicates that lower lung volumes, greater non-specific bronchial hyper-responsiveness (NSBH) and stronger asthmatic response to specific inhalation challenge (SIC) at diagnosis are risk factors for the poor outcome of OA. ${ }^{1}$ Ideally, the worker should be removed from the work environment causing asthma, in order to prevent the deterioration of respiratory condition. However, complete cessation of 
exposure has high socioeconomic consequences and is thus rarely feasible. ${ }^{2}$ Recent systematic literature research suggests that longer symptomatic exposure is associated with worse OA outcome, in terms of persistence of symptoms and NSBHR and greater decline in forced expiratory volume in $1 \mathrm{~s}$ (FEV1). ${ }^{3}{ }^{4}$ Some studies have evaluated the outcome of functional parameters after diagnosis (revised in ref. 5). Two retrospective cohort studies documented accelerated FEV1 decline in patients with OA before removal from the causal agents ${ }^{5}{ }^{6}$; in one of these studies, ${ }^{6}$ FEV1 continued to decline after removal from exposure, but at a slower rate, similar to the rate of decline observed in healthy adults. Data about the effect of antiasthma medication on symptoms and lung function in patients with persistent exposure are contradictory. ${ }^{6} 7$

However, OA may have different outcomes, and it is unknown whether these differences depend on the underlying inflammatory process and structural changes in the airways. Different phenotypic categories have been reported according to clinical or inflammatory characteristics, or to the triggers inducing or aggravating asthma. ${ }^{8}$ Eosinophilic and non-eosinophilic phenotypes have been described. ${ }^{9}$ A recent study reported a rapid decrease in eosinophilic inflammation after removal from exposure, but participants with non-eosinophilic asthmatic reaction during SIC seemed to have a poorer prognosis than participants with SIC-induced eosinophilic airway inflammation at diagnosis. ${ }^{10}$

The aim of this study was to evaluate the possible determinants of FEV1 decline in workers with OA still exposed to the causative agent.

\section{PATIENTS AND METHODS}

We studied 39 participants previously diagnosed as having OA, routinely followed up at the CardioThoracic and Vascular Department of the University Hospital of Pisa between 1990 and 2009. They were only a subgroup of the 94 participants diagnosed as affected by $\mathrm{OA}$ in that period. Of the whole group, 9 participants had been completely removed from work at the time of diagnosis, while 21 participants were excluded for having ceased occupational exposure few months after diagnosis, and 25 participants were lost at the follow-up or had no acceptable sputum measurements at the diagnosis. There was no difference in the main clinical and functional data between the 39 participants included in this study and the other 46 participants still at work at the time of the diagnosis and not included in this study (see online supplementary table $1 \mathrm{~A}$ in the appendix).

The diagnosis of OA was made at the first evaluation, according to the positive response to the SIC test: 23 participants were sensitised to low-molecular-weight compounds (LMWC: isocyanates and persulfate salts) and 16 participants to high-molecular-weight compounds (HMWC: flour dusts, wood dusts, latex and tobacco dusts).
All participants were routinely evaluated every 6 months after diagnosis, while still exposed to the specific sensitiser at work. The duration of follow-up was $5.7 \pm 3.7$ years.

At the first evaluation, all patients were interviewed about asthmatic symptoms and occupational exposure, and underwent spirometry and methacholine challenge tests, prick test to common airborne allergens, collection of sputum for inflammatory cells count, and SIC test with the specific occupational agent.

At each follow-up examination, asthmatic symptoms, pharmacological therapy, type of occupational exposure (persistent vs reduced exposure) and spirometric data were collected. Work exposure was considered as persistent when the patient continued working with the same job title and in the same environment, whereas it was considered as reduced when the patient had been relocated in another area of the same factory where the specific sensitiser was not used, with occasional short-term direct exposure to the specific sensitiser. ${ }^{11}$

Antiasthma treatment was withdrawn $48 \mathrm{~h}$ before spirometry.

\section{Pulmonary function tests, atopy and symptoms evaluation} FEV1 and forced vital capacity were measured by a computerised water-sealed spirometer (Biomedin, Padova, Italy) using predicted values approved by the European Respiratory Society. The details of the methacholine challenge test have been reported previously. ${ }^{12}$ The cumulative dose of methacholine producing a $20 \%$ fall in FEV1 (provocative dose of methacholine causing a $20 \%$ reduction in FEV1, PD20FEV1) was computed; a PD20FEV1 value $<1000 \mu \mathrm{g}$ of methacholine was considered as positive for NSBH.

SIC was performed using two different methods: (1) for diisocyanates, participants were exposed to vapours of toluenediisocyanate or methylendiisocyanate, and the duration of the exposure was the same $(30 \mathrm{~min})$ for all participants. FEV1 was measured before and immediately after exposure, then hourly for $8 \mathrm{~h}^{12}$ and (2) for dusts, participants were asked to breathe through a mouthpiece connected to a small box where a measured suspension of the dust was obtained. ${ }^{13} \mathrm{~A}$ positive response was defined as a decrease in FEV1 greater than $15 \%$ from baseline within the first hour (immediate response) or between the second and the eighth hour (late response), and in the absence of a greater than $10 \%$ decrease in FEV1 during a control test performed with a diluent (for diisocyanates) or with lactose dust (for other sensitisers).

Current asthma symptoms (more than 2 times/week) and antiasthma therapy (defined as regular use of inhaled corticosteroids (ICS)) were recorded as qualitative parameters (yes/no) at each visit.

\section{Sputum induction and processing}

Sputum was induced according to the European Respiratory Society Task Force recommendations. ${ }^{14}$ Hypertonic saline solution $(\mathrm{NaCl} 4.5 \%)$ was nebulised by 
means of an ultrasonic nebuliser (Ultraneb 2000, DeVilbiss, Somerset, Pennsylvania, USA) with $2.8 \mathrm{~mL} / \mathrm{min}$ output, and was inhaled for three 5 min periods for up to $15 \mathrm{~min}$. Every $5 \mathrm{~min}$, after the start of nebulisation, participants were asked to rinse their mouth and throat carefully, to discard saliva, and to try to cough sputum into a container; FEV1 was then measured. Nebulisation was stopped after 15 min or when FEV1 fell by $\geq 20 \%$ from baseline value. Saline-induced bronchoconstriction was promptly relieved by short-acting $\beta 2$-agonist inhalation. Sputum samples were diluted with an equal volume of $0.1 \%$ dithiothreitol (Sputasol, Unipath, Basingstoke, UK). Samples were treated as previously reported. ${ }^{15}$ Macrophages, lymphocytes, neutrophils and eosinophils were expressed as the percentage of total inflammatory cells, excluding squamous cells. The upper limit of the normal range for sputum eosinophils was set at $3 \%$ as derived from a group of normal participants, whereas high sputum neutrophils were defined when the sputum neutrophil percentage was $>63 \%{ }^{16}$

\section{Statistical analysis}

FEV1 is expressed as the mean \pm SD. PD20FEV1 is expressed as the geometric mean and is log-transformed for comparisons. The sputum cell count is expressed as the median (range). Simple regression analysis was used to provide estimates of the decline in FEV1 (expressed as the annual average change in FEV1) during the period of occupational exposure. Categorical data were compared by using Pearson's $\chi^{2}$ statistics. Continuous data were compared using unpaired Student t test or Mann-Whitney test.

Logistic regression was used to analyse the effects of potential factors measured at baseline (independent variables: baseline FEV1, PD20FEV1 methacholine, sputum eosinophils and neutrophils and other general or clinical characteristics such as atopy, smoking habit and duration of exposure) on the dependent variables (decline $>-57.5 \mathrm{~mL} /$ year, the lowest tertile of the distribution of single FEV1 declines). In the analysis, we also included two variables that may potentially modify FEV1 decline during follow-up: (1) persistence or reduction of occupational exposure to the sensitiser (we considered as reduced the exposure to the sensitiser for less than $100 \%$ but more than $50 \%$ of the follow-up period) and (2) ICS therapy (we considered as ICS-treated patients those who used ICS for more than 50\% of the follow-up period including the last visit).

The results are given in terms of ORs with $95 \%$ CI. Dependent and independent categorical variables were binary (high vs low sputum eosinophils, high vs low sputum neutrophils, hyper-reactivity vs no hyperreactivity, persistence vs reduction of exposure, smoker and ex-smoker vs non-smoker, LMWC vs HMWC, ICS therapy vs no therapy), whereas continuous variables (age, baseline FEV1, duration of exposure) were transformed into categorical variables with the tertile distribution obtained for all patients; in particular, the highest tertile (for age, duration of exposure and time to removal) or the lowest tertile (for FEV1) was associated with the presence of the condition.

\section{RESULTS}

Table 1 shows the general characteristics of patients at the time of diagnosis. LMWC were the main agents causing OA, with isocyanates causing asthma in 19 patients $(48 \%)$.

Clinical and functional findings of patients at the time of diagnosis and at the last visit of follow-up are reported in table 2. At the time of diagnosis, all but two of the six patients who had already reduced their occupational exposure to the specific sensitiser had current asthma symptoms and NSBH, whereas the mean FEV1 was normal and sputum eosinophilia was observed in less than $50 \%$ of patients.

At follow-up, FEV1 (in L) was lower than that measured at diagnosis $(\mathrm{p}<0.001)$, but FEV1 expressed as \% of predicted and PD20FEV1 methacholine was no different from baseline; also, the number of patients with NSBH was not significantly different between diagnosis and follow-up. At the time of diagnosis, six patients had already reduced their occupational exposure to the specific sensitiser, because they had been relocated to another job in the same factory with occasional, indirect exposure to the sensitiser. At follow-up, a further 20 patients had reduced their exposure to the sensitising agent. More patients were treated with ICS at the last visit of follow-up in comparison with baseline $(\mathrm{p}<0.001)$, but $43.6 \%$ still reported asthma symptoms, although generally of mild severity, and in lower percentage than at diagnosis $(p<0.001)$. All these changes were similar between patients who had persistent or reduced exposure to the occupational sensitiser, except for PD20FEV1 which was increased in participants who had reduced exposure.

Table 1 General characteristics of the patients at the time of diagnosis

\begin{tabular}{ll}
\hline Number & 39 \\
Age, years & $43.5 \pm 11.8$ \\
Sex, M/F & $28 / 11$ \\
Smoke, Yes/Ex/No & $3 / 20 / 16$ \\
Atopy, $\mathrm{n}(\%)$ & $13(33.3)$ \\
Duration of exposure, years & $18.6 \pm 11.1$ \\
Latency, years & $12.8 \pm 10.9$ \\
Agents & \\
$\quad$ LMWC & 23 \\
$\quad$ Isocyanates & 19 \\
$\quad$ Persulfate salts & 4 \\
$\quad$ HMWC & 16 \\
$\quad$ Flour dusts & 11 \\
$\quad$ Wood dusts & 2 \\
$\quad$ Latex & 2 \\
$\quad$ Tobacco dusts & 1 \\
\hline F, female; HMWC, high-molecular-weight compounds; LMWC, \\
low-molecular-weight compounds; M, male.
\end{tabular}


Table 2 Clinical and functional findings at baseline and at the last visit of follow-up

\begin{tabular}{|c|c|c|}
\hline & Diagnosis & Follow-up (5.7 \pm 3.7 years) \\
\hline Reduction of exposure, $\mathrm{n}(\%)$ & $6(15.4)$ & $26(66.7)^{\star}$ \\
\hline $\mathrm{FEV} 1, \mathrm{~mL}$, mean $\pm \mathrm{SD}$ & $3.12 \pm 0.57$ & $2.92 \pm 0.55^{\star}$ \\
\hline FEV1, \% of predicted, mean+SD & $94.1 \pm 16.1$ & $92.2 \pm 14.8$ \\
\hline PD20FEV1, $\mu \mathrm{g}, \mathrm{GM}$ (SD) & $227(1437)$ & $228(1757)$ \\
\hline $\mathrm{NSBH}, \mathrm{n}(\%)$ & $33(84.6)$ & $28(71.8)$ \\
\hline ICS therapy, n (\%) & $14(35.9)$ & $36(92.3)^{*}$ \\
\hline Patients with current symptoms, n (\%) & $32(82.1)$ & $17(43.6)^{\star}$ \\
\hline Sputum eosinophils \%, median (range) & $2.9(0-43.1)$ & NA \\
\hline Sputum eosinophils >3\%, n (\%) & $19(48.7)$ & NA \\
\hline
\end{tabular}

${ }^{*} p<0.001$ between diagnosis and follow up.

FEV1, forced expiratory volume in the first second; GM, geometric mean; ICS, inhaled corticosteroids; NA, not applicable; NSBH, non-specific bronchial hyper-responsiveness; PD20FEV1, provocative dose of methacholine causing a $20 \%$ reduction in FEV1; SD, standard deviation.

Using simple regression analysis, we provided estimates of the decline of FEV1 (expressed as the annual average change in FEV1) during the period of occupational exposure in all participants. The median annual decline in FEV1 in all participants was $-30.9 \mathrm{~mL} /$ year (range -188.3 to $+57.9 \mathrm{~mL} /$ year). Using separate regression lines to separate periods of reduced exposure from periods of original exposure (available data only in 9 patients), the median estimate FEV1 slope during the period of persistent exposure was much higher than in the period of reduced exposure to the causative agent $(-166.4(-354.9$ to -57.7$)$ vs $-7.9(-129.3$ to 55.8$) \mathrm{mL} /$ year, $\mathrm{p}=0.001$ ). When we compared patients with a different decline in FEV1 (according to the tertile distribution, from patients with lowest decline, $<-16.9 \mathrm{~mL} /$ year, to patients with highest decline, $>-57.5 \mathrm{~mL} /$ year) as regards baseline characteristics, we did not observe any significant difference among different decliners except for baseline FEV1, which was significantly higher in patients with the highest decline (table 3 ). The group with the lowest FEV1 decline included only patients with persistent exposure. Atopic patients were more represented in the group with the highest decline, although the difference was not significant.
Participants with higher sputum eosinophils $(>3 \%)$, as well as participants with persistent exposure, had a significantly greater decline in FEV1 (figure 1) $(p=0.012)$ when compared to those who had reduced their exposure to the occupational sensitiser (figure 2) $(p=0.03)$.

Using a univariate analysis, we estimated the decline in FEV1 (using as an independent variable the highest tertile of FEV1 decline: $-57.5 \mathrm{~mL}$ /year) in relationship to baseline FEV1, baseline eosinophil ( $>3 \%$ vs $<3 \%$ ) and neutrophil ( $>63 \%$ vs $<63 \%$ ) levels, level of exposure at follow-up (persistence vs reduction of exposure), smoking habit (ex-smokers or current smokers vs non-smokers), molecular weight of the sensitiser (LMWC vs HMWC), duration of exposure and use of ICS during the follow-up. Persistent exposure (OR 6.7 (1.5 to 29.6), $\mathrm{p}=0.012$ ), higher baseline sputum eosinophil levels (OR 3.6 (0.8 to 14.8), $\mathrm{p}=0.07$ ) and baseline FEV1 (\% of predicted) (OR 1.04 (0.99 to 1.1$), \mathrm{p}=0.07$ ) significantly correlated with a greater decline in FEV1. Table 4 shows results of a multivariate analysis when persistent exposure, higher baseline sputum eosinophil levels and baseline FEV1 (\% of predicted) were used as independent variables. Persistent exposure and higher baseline sputum eosinophil levels significantly correlated with a greater decline in FEV1.

Table 3 Characteristics of patients at baseline, grouped by FEV1 decline during the follow-up

\begin{tabular}{llll}
\hline & $<-16.9$ mL/year & $\mathbf{- 1 6 . 9}$ to $\mathbf{- 5 7 . 5}$ mL/year & $>-57.5$ mL/year \\
\hline Number of patients & 13 & 13 & 13 \\
Age, years, mean+SD & $43.8+12.7$ & $44.2+11.9$ & $42.4+11.6$ \\
Gender, M/F & $10 / 3$ & $8 / 5$ & $10 / 3$ \\
Smoke, No/Ex/Yes & $4 / 7 / 2$ & $7 / 5 / 1$ & $5 / 8 / 0$ \\
Atopy, $n$ (\%) & $2(15.4)$ & $4(30.8)$ & $7(53.8)$ \\
LMWC/HMWC & $8 / 5$ & $7 / 6$ & $8 / 5$ \\
FEV1, \% predicted, mean \pm SD & $84.8+15.2$ & $97.4+14.3$ & $100.9+14.6^{*}$ \\
PD20FEV1, $\mu$ g, GM (SD) & 196 & 149 & 399 \\
Bronchial hyper-reactivity, $n(\%)$ & $12(92.3)$ & $11(84.6)$ & $10(76.9)$ \\
Reduction of exposure, n (\%) & 0 & $5(38.5)$ & $1(7.7)$ \\
Sputum eosinophil \%, median (range) & $2.3(0-15.5)$ & $2.0(0.43 .1)$ & $4.9(0-24.4)$ \\
Sputum neutrophil \%, median (range) & $59.5(30.8-86.7)$ & $37.0(11.1-85.0)$ & $47.2(19.4-96.0)$ \\
\hline
\end{tabular}

${ }^{*} p<0.05$ among the three groups.

F, female; FEV1, forced expiratory volume in the first second; GM, geometric mean; HMWC, high-molecular-weight compounds; LMWC, lowmolecular-weight compounds; M, male; PD20FEV1, provocative dose of methacholine causing a $20 \%$ reduction in FEV1; SD, standard deviation. 


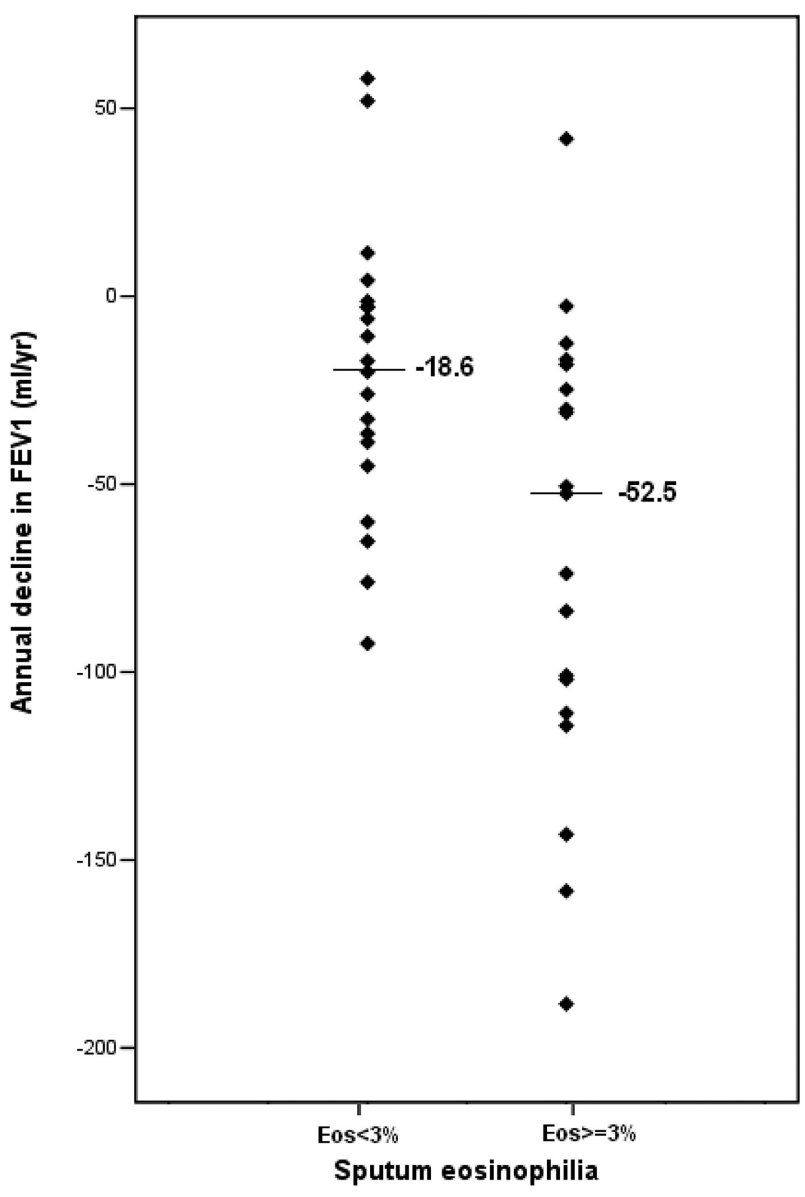

Figure 1 Forced expiratory volume in the first second (FEV1) decline according to the baseline sputum eosinophilia.

\section{DISCUSSION}

The present study confirms that the prognosis of OA is poor in participants who remain exposed to the sensitising agent, as shown by the persistence of symptoms and airway hyper-responsiveness in many patients. Furthermore, it demonstrates for the first time that the highest rate of decline in FEV1 during the follow-up was associated with a high $(>3 \%)$ sputum eosinophil count at the initial evaluation and with the persistence of exposure to the causal agent, suggesting that baseline eosinophilic airway inflammation may contribute, together with the persistence of occupational exposure, to a poor asthma outcome.

In 280 patients with red cedar asthma with persistent exposure, a greater rate of decline in FEV1 was observed in comparison with asymptomatic sawmill workers. ${ }^{5}$ Piirilä et $a l^{17}$ reported a mean rate of decline of $40 \mathrm{~mL} /$ year in 91 selected participants with isocyanate-induced OA, although only 12 of these continued to be exposed to the causative agent in the workplace during the period of follow-up. Anees studied 90 participants undergoing FEV1 measurements at least once yearly before removal from exposure. ${ }^{6}$ In this study, FEV1 rapidly declined in exposed workers with OA; after removal from exposure, FEV1 continued to decline but

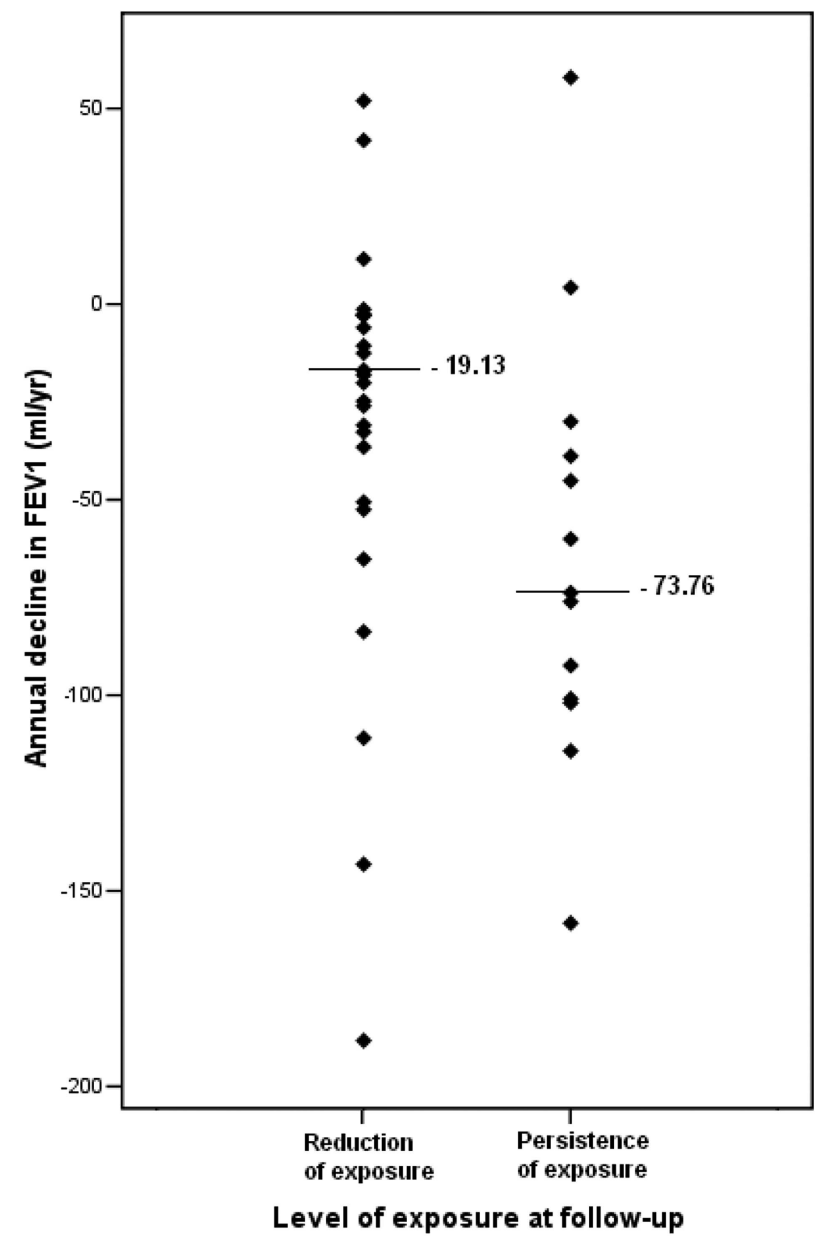

Figure 2 Forced expiratory volume in the first second (FEV1) decline according to the level of exposure at follow-up.

at a slower rate, similar to the rate of decline observed in healthy adults. The nature of the causative agent, current smoking or treatment with ICS did not seem to affect the rate of decline in FEV1. However, the authors could not estimate the decline in FEV1 any further because the follow-up assessments after removal from exposure were less close and the model of linear decline following the step-up period might have masked intra-individual variation in the pattern of recovery.

In our study, we investigated the determinants of FEV1 decline in patients with OA, after diagnosis and during the follow-up period, when they were either fully or partially exposed to the specific sensitiser. We observed that baseline FEV1 was inversely related to its own decline, in agreement with what had already been published in asthmatic patients and in the general population. ${ }^{5} \mathrm{On}$ the contrary, we found no significant relationship between bronchial hyper-responsiveness and FEV1 decline, in agreement with the observation that there was no difference between PD20FEV1 at diagnosis and at follow-up, nor did we confirm what observed in a previous paper $^{19}$ regarding the relationship between smoking habit or atopy and FEV1 decline. 
Table 4 Results of the multivariate analysis on the main determinants of the FEV1 decline, including as independent variables only those variables significantly related to the FEV1 decline in the univariate analysis

\begin{tabular}{|c|c|c|c|c|}
\hline \multirow[b]{2}{*}{ Variables } & \multirow{2}{*}{$\begin{array}{l}\text { Odd } \\
\text { ratios }\end{array}$} & \multicolumn{2}{|l|}{$95 \% \mathrm{Cl}$} & \multirow[b]{2}{*}{ p Value } \\
\hline & & Lower & Upper & \\
\hline $\begin{array}{l}\text { Persistent exposure vs } \\
\text { reduction }\end{array}$ & 12.7 & 1.8 & 90.8 & 0.01 \\
\hline $\begin{array}{l}\text { Sputum eosinophilia } \\
\geq 3 \%\end{array}$ & 7.6 & 1.1 & 52.9 & 0.04 \\
\hline $\begin{array}{l}\text { Baseline FEV1 (\% of } \\
\text { predicted) }\end{array}$ & 1.06 & 0.99 & 1.13 & 0.06 \\
\hline
\end{tabular}

Previous studies ${ }^{20} 21$ have shown an association between high eosinophil levels and accelerated FEV1 decline in adult patients with asthma, thereby postulating a role for eosinophils in the progression of the disease. On the other hand, Lemiere et $a l^{10}$ studied a sample of 24 patients with OA removed from exposure after diagnosis, and identified a non-eosinophilic phenotype that showed significant FEV1 decline, along with a lack of improvement in airway responsiveness during the 4-year follow-up period after cessation of exposure. By contrast, the eosinophilic phenotype showed a less marked FEV1 decline, significant decrease in ICS use over time and a trend towards improvement in airway responsiveness. On the basis of these findings, it is tempting to speculate that the accelerated FEV1 decline in asthma may result from the progressive airway remodelling process in which neutrophilic inflammation is also likely to play an important role.

In our study, we found a significant relationship between baseline sputum eosinophil levels and FEV1 decline, suggesting that higher levels of inflammation at baseline may cause an accelerated decline in FEV1. To the best of our knowledge, no previous paper has considered this biomarker as a possible determinant of the decline in FEV1 in patients with OA who continued to work. Broekema et $a l^{21}$ showed that asthmatic patients with an accelerated FEV1 decline had high sputum eosinophil levels, but the sputum was analysed at the end of follow-up, and we cannot therefore exclude that sputum eosinophilic inflammation is not the cause but rather the consequence of the accelerated FEV1 decline in this study. Unfortunately, in our experience, sputum analysis at the end of occupational exposure was available in only eight participants.

As in the study by Lemiere et $a l^{10},{ }^{10}$ we found no significant relationship between ICS therapy and FEV1 decline. Non-eosinophilic asthma may be less responsive to ICS treatment than eosinophilic asthma: although Dijkstra $e t a l^{22}$ found that oral or ICS reduced FEV1 decline in asthma, some authors have suggested that the lack of eosinophilic inflammation may be a characteristic of refractory asthma. ${ }^{23}$ This fact may suggest the need for specific adjustment of asthma treatment according to the characteristics of airway inflammation.

Our study has some limitations. First, the number of patients examined is relatively small. In effect, several patients with a diagnosis of $\mathrm{OA}$ ceased work in the 6 months after diagnosis, or were lost at the first follow-up visit. However, apart from few studies enrolling a large number of patients, several other published studies have included a similar number of patients. ${ }^{10}$ Second, the type of exposure (LMWC vs HMWC) was heterogeneous, but again this is frequently reported in many previous studies. Finally, the distinction between persistence and reduction of exposure is not based on specific environmental measurements, but the majority of previous studies used the same rough distinction we did between patients who continued and patients who reduced occupational exposure to the specific sensitiser (reviewed in ref. 24).

In conclusion, we demonstrated that in a wellcharacterised group of patients with OA, sputum eosinophilia at diagnosis is one determinant of the accelerated decline in FEV1 when patients are still at work. Further long-term studies are required as to whether intensive ICS treatment may be beneficial for patients with OA and increased eosinophilic inflammation.

Contributors DT and FN conceived and designed the original paper. All authors were involved in amending the protocol. DT coordinated the study throughout. Data entry was carried out by DT and FN. MB and SC have analysed the biological determinants. EB, FC, FLD, ADF, ML, LM, BV and AC dealt with the clinical assessment of patients. PP supervised the work and reviewed the paper.

\section{Competing interests None.}

Provenance and peer review Not commissioned; externally peer reviewed.

Data sharing statement No additional data are available.

Open Access This is an Open Access article distributed in accordance with the Creative Commons Attribution Non Commercial (CC BY-NC 4.0) license, which permits others to distribute, remix, adapt, build upon this work noncommercially, and license their derivative works on different terms, provided the original work is properly cited and the use is non-commercial. See: http:// creativecommons.org/licenses/by-nc/4.0/

\section{REFERENCES}

1. Mapp CE, Boschetto $\mathrm{P}$, Maestrelli $\mathrm{P}$, et al. Occupational asthma. Am $J$ Respir Crit Care Med 2005;172:280-305.

2. Yacoub MR, Lavoie $\mathrm{K}$, Lacoste $\mathrm{G}$, et al. Assessment of impairment/ disability due to occupational asthma. Through a multidimensional approach. Eur Respir J 2007;29:889-96.

3. Baur X, Sigsgaard T, Aasen TB, et al. ERS task force report Guidelines for the management of work-related asthma. Eur Respir $J$ 2012;39:529-45.

4. DeGroene GJ, Pal TM, Beach J, et al. Workplace interventions for treatment of occupational asthma: a cochrane systematic review. Occup Environ Med 2012;69:373-4.

5. Lin FJ, Dimich-Ward H, Chan-Yeung M. Longitudinal decline in lung function in patients with occupational asthma due to western red cedar. Occ Envir Med 1996;53:753-6.

6. Anees W, Moore VC, Burge PS. FEV1 decline in occupational asthma. Thorax 2006;61:751-5.

7. Marabini A, Dimich-Ward H, Kwan SY, et al. Clinical and socioeconomic features of subjects with red cedar asthma. A follow-up study. Chest 1993;104:821-4.

8. Wenzel SE. Asthma: defining of the persistent adult phenotypes. Lancet 2006;368:804-13.

9. Douwes J, Gibson P, Pekkanen J, et al. Non eosinophilic asthma: importance and possible mechanism. Thorax 2002;57:643-8. 
10. Lemiere C, Chaboillez S, Welman M, et al. Outcome of occupational asthma after removal from exposure: a follow-up study. Can Respir J 2010;17:61-6.

11. Talini D, Novelli F, Melosini L, et al. May the reduction of exposure to specific sensitizers be an alternative to work cessation in occupational asthma? Results from a follow-up study. Int Arch Allergy Immunol 2012;157:186-93.

12. Paggiaro $\mathrm{PL}$, Vagaggini $B$, Dente $\mathrm{FL}$, et al. Bronchial hyperresponsiveness and toluene diisocyanate. Long-term change in sensitized asthmatic subjects. Chest 1993;103:1123-8.

13. Talini D, Benvenuti A, Carrara M, et al. Diagnosis of flour-induced occupational asthma in a cross-sectional study. Respir Med 2002;96:236-43.

14. Paggiaro PL, Chanez $\mathrm{P}, \mathrm{Holz} \mathrm{O}$, et al. Sputum induction. Eur Respir J Supp/ 2002;37:3s-8s.

15. Bacci E, Cianchetti S, Paggiaro PL, et al. Comparison between hypertonic and isotonic saline-induced sputum in the evaluation of airway inflammation in subjects with moderate asthma. Clin Exp Allergy 1996;26:1395-400.

16. Spanevello A, Confalonieri M, Sulotto F, et al. Induced sputum cellularity. Reference values and distribution in normal volunteers. Am J Respir Crit Care Med 2000;162:1172-4.

17. Piirilä PL, Nordman H, Keskinen HM, et al. Long-term follow-up of hexamethylene diisocyanate-, diphenylmethane diisocyanate-, and toluene diisocyanate-induced asthma. Am J Respir Crit Care Med 2000;162:516-22.

18. Burrows B, Knudson RJ, Camilli AE, et al. The "horse-racing effect" and predicting decline in forced expiratory volume in one second from screening spirometry. Am Rev Respir Dis 1987;135:788-93.

19. Frew AJ, Kennedy SM, Chan-Yeung M. Methacholine responsiveness, smoking, and atopy as risk factors for accelerated FEV1 decline in male working populations. Am Rev Respir Dis 1992;146:878-83.

20. Ulrik CS, Backer V, Dirksen A. A 10 year follow up of 180 adults with bronchial asthma: factors important for the decline in lung function. Thorax 1992;47:14-18.

21. Broekema M, Volbeda F, Timens W, et al. Airway eosinophilia in remission and progression of asthma: accumulation with a fast decline of FEV1. Respir Med 2010;104:1254-62.

22. Dijkstra A, Vonk JM, Jongepier $\mathrm{H}$, et al. Lung function decline in asthma: association with inhaled corticosteroids, smoking and sex. Thorax 2006;61:105-10.

23. Pavord ID, Brightling CE, Woltmann G, et al. Non-eosinophilic corticosteroid unresponsive asthma. Lancet 1999;353:2213-14.

24. Vandenplas $\mathrm{O}$, Dressel $\mathrm{H}$, Wilken D, et al. Management of occupational asthma: cessation or reduction of exposure? A systematic review of available evidence. Eur Respir $J$ 2011;38:804-11. 